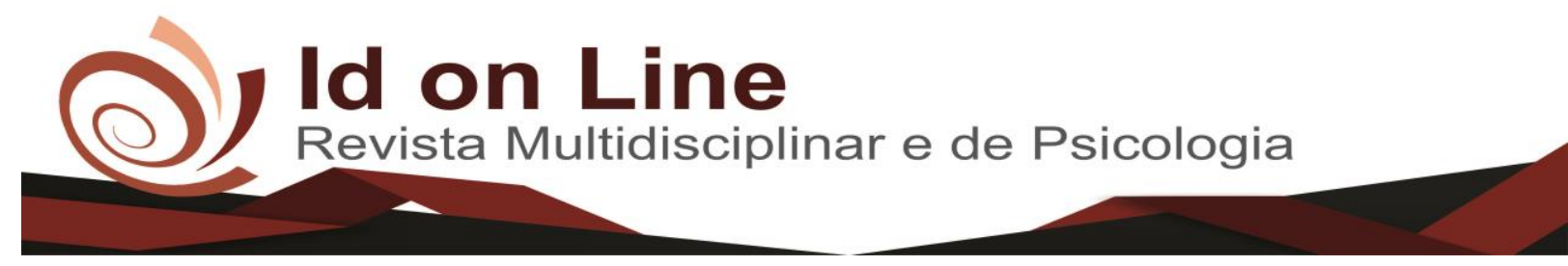

Comment

\title{
O Início da Epidemia do Zika Vírus e os seus Reflexos na Saúde Pública Nacional e Internacional
}

\author{
Cícera Nerilda Vieira Petrônio ${ }^{1}$, Antonio Marlos Duarte de Melol, Edmar Mesquita Neto ${ }^{1}$, José Angelo Araújo Sampaio ${ }^{1}$,
} Maria Valéria Leimig Telles ${ }^{1}$, Conceição Maria Santos Correia de Souza ${ }^{1}$

\begin{abstract}
Resumo: No final do ano de 2015, observou-se um aumento exponencial no número de casos notificados de recém nascidos com microcefalia, definida pela medida do perímetro cefálico (PC) menor que dois desvios padrões em relação a média populacional, para dado sexo e idade gestacional, segundo a Organização Mundial de Saúde (OMS). Em consonância a isso, a infecção pelo Zika vírus (ZIKV), uma arbovirose emergente no país, tornou-se uma endemia. Este trabalho tem como objetivo estudar a associação da infecção intra-útero pelo Zika vírus e a ocorrência de microcefalia no período neonatal, apresentando os dados mais recentes referente à etiologia, epidemiologia e fisiopatologia da Síndrome do Zika vírus, além de descrever os desfechos relacionados a exposição ao ZIKV na gestação e avaliar o prognóstico das crianças afetadas pela microcefalia. Foi realizada uma revisão de literatura a partir de artigos científicos, livros e boletins epidemiológicos na elaboração do presente estudo. Assim, verificou-se que os portadores de microcefalia associada ao ZIKV apresentam atraso importante no desenvolvimento neuropsicomotor associado a alterações visuais, auditivas e sensoriais, o que irá impactar na independência funcional e na inserção social dos mesmos. Ainda são escassos os conhecimentos sobre essa síndrome, tanto sobre sua evolução natural, como dos seus fatores de risco ou associados, sendo necessários mais estudos sobre a temática.
\end{abstract}

Palavras-chave: "Vírus Zika", "Gestação", "Microcefalia".

\section{The Beginning of the Zika Virus Epidemic and its Reflexes in National and International Public Health}

\begin{abstract}
At the end of the year 2015, there was an exponential increase in the number of reported cases of newborns with microcephaly, defined by cephalic perimeter $(\mathrm{CP})$ less than two standard deviations in relation to the population mean, for sex and gestational age, according to the World Health Organization (WHO). Consistent with this, infection by Zika virus (ZIKV), an emerging arbovirus in the country, has become an endemic. This study aims to study the association of intra-uterine infection with Zika virus and the occurrence of microcephaly in the neonatal period, presenting the most recent data regarding the etiology, epidemiology and pathophysiology of Zika virus, and to describe the outcomes related to exposure to ZIKV during gestation and to evaluate the prognosis of children affected by microcephaly. A review of the literature was made from scientific articles, books and epidemiological bulletins in the elaboration of the present study. Thus, it was verified that ZIKV-associated microcephaly patients present a significant delay in the neuropsychomotor development associated with visual, auditory and sensory alterations, which will impact their functional independence and their social insertion. The knowledge about this syndrome is still scarce, both on its natural evolution, its risk factors or associated, and more studies on the subject are necessary.
\end{abstract}

Keywords: "Zika virus", "Gestation", "Microcephaly".

\footnotetext{
${ }^{1}$ Faculdade de Medicina Estácio de Juazeiro do Norte (Estácio-FMJ), Juazeiro do Norte, Ceará, Brasil. Autora correspondente: Cícera Nerilda Vieira Petrônio - Curso de Medicina da Estácio-FMJ. Rua Tenente Raimuno Rocha, 515, Cidade Universitária, Juazeiro do Norte, Ceará, Brasil. CEP 63048-080. E-mail: cnerildapetronio@gmail.com
} 


\section{Refletindo sobre o Zika Vírus}

O aparecimento de enfermidades emergentes tem gerado uma grande preocupação na comunidade científica internacional. As arboviroses se inserem dentro desse grupo de patologias e, ao longo destes últimos anos, apresentaram frequência ampla de notificação por parte dos órgãos de controle epidemiológico de doenças infecciosas. A palavra "arbovirose" deriva da expressão inglesa Athropode Borne Viruses, usada para designar um grupo de infecções virais transmissíveis para os hospedeiros definitivos por meio de vetores artrópodes hematófagos (DE OLIVEIRA; VASCONCELOS, 2016; FERNÁNDEZ-SANLÉS et al., 2017). O aumento alarmante de casos de arboviroses evidenciados pode ser justificado como decorrente dos processos de globalização das várias atividades humanas, como as viagens internacionais, o que permite o contato entre pessoas das mais diversas partes do planeta (CIPRIANO; MONTEIRO, 2016). Dentre as arboviroses mais importantes atualmente para a saúde pública global, estão aquelas causadas pelos vírus da família Flaviviridae, na qual estão compreendidos o vírus Zika (ZIKV), o vírus da Dengue (DENV), o vírus da Encefalite Japonesa (JEV), o vírus da Chikungunya (CHIKV) e o vírus da Febre Amarela (YFV). Além de pertencerem à mesma família, esses agentes etiológicos pertencem também ao mesmo gênero Flavivirus.

Os vírus da família Flaviviridae possuem genoma de ácido ribonucleico (RNA) de cadeia linear simples, retido por um capsídeo de simetria icosaédrica que, por sua vez, está envolto por uma bicamada lipídica, formando o envelope viral no qual são inseridas a proteína viral de membrana $(\mathrm{M})$ e a glicoproteína de envelope (E), originando uma partícula esférica com 40 a 60 nm de diâmetro. (MURRAY; ROSENTHAL; PFALLER, 2013). Dentre as arboviroses analisadas, a infecção pelo vírus Zika surgiu como uma ameaça pandêmica nos últimos anos, sendo transmitidas como vetores os mosquitos do gênero Aedes, especialmente as espécies $A$. aegypti e A. albopictus. Além de existir esta transmissão vetorial, o ZIKV também pode ser transmitido por contato sexual, transfusão de sangue ou ainda por transmissão vertical (OLIVEIRA, 2017).

Apesar de não haver um consenso a respeito do primeiro caso de infecção pelo vírus Zika na espécie humana, entende-se que os primeiros relatos foram feitos entre as décadas de 50 e de 60 do século 20, no continente africano. Poucos foram os casos notificados até 2007, quando houve uma epidemia da doença na Micronésia (CIPRIANO; MONTEIRO, 2016). É 
importante lembrar que a baixa incidência de casos no intervalo de aproximadamente cinquenta anos não significa que a doença não ocorreu durante este período, mas também quando se considera a semelhança dos sinais e sintomas provocados por este vírus com as apresentadas por outras arboviroses e a reação cruzada que comumente pode ocorrer com outros vírus intimamente relacionados, o que pode ter conduzido a diagnósticos errados (BAUD et al., 2017).

A maioria dos flavivírus estão intimamente relacionada e os anticorpos desses vírus podem dar reação cruzada entre eles (MURRAY; ROSENTHAL; PFALLER, 2013). A recente e atual disseminação do vírus Zika nos contimentes africano, asiático, americano e europeu também influiu o aparecimento de desordens neurológicas decorrentes da infecção pelo ZIKV, como a Síndrome de Guillain-Barré e a síndrome congênita do Zika.

Em 2016, a epidemia chegou ao seu maior patamar no Brasil, tendo sido confirmados cerca de 110 mil casos dos pouco mais de 200 mil casos registrados (BRASIL, 2017). A associação do aumento de casos de microcefalia com surtos de infecção pelo vírus Zika, ocorridos no Brasil a partir do final de 2014, principalmente no Nordeste, passou a ser objeto de investigações das autoridades epidemiológicas no país (SOUZA et al., 2016).

Conclui-se que ainda são escassos os conhecimentos sobre essa síndrome, tanto sobre sua evolução natural, como dos seus fatores de risco ou associados. Desconhecemos a frequência de abortos e morte fetal ou neonatal, assim como todo o espectro de comprometimento das crianças afetadas e o grau de gravidade prognóstica a longo prazo das mesmas.

É fundamental explorar-se outros critérios clínicos e/ou fenotípicos, bem como achados em exames por imagem, na definição de um padrão-ouro mais acurado, orientando, de forma mais efetiva, a notificação, a investigação e a assistência dos casos.

\section{Referências}

\section{BAUD, D. et al. An update on Zika virus infectionThe Lancet, 2017.}

BRASIL, Ministério da Saúde. Secretaria de Vigilância em Saúde. Vírus Zika no Brasil: a resposta do SUS, [R.E]. Ministério da Saúde, Secretaria de Vigilância em Saúde.

Brasília., 2017. 
CIPRIANO, R.; MONTEIRO, C. C. Relato sobre o Zika vírus no Brasil A report about Zika virus in Brazil. Revista de Epidemiologia e Controle de Infecção, v. 6, p. 4-7, 2016.

DE OLIVEIRA, C. S.; VASCONCELOS, P. F. C. Microcephaly and Zika virus. Jornal de Pediatria, v. 92, n. 2, p. 103-105, 2016.

FERNÁNDEZ-SANLÉS, A. et al. Functional information stored in the conserved structural RNA domains of flavivirus genomes. Frontiers in Microbiology, 2017.

MURRAY, P. R.; ROSENTHAL, K. S.; PFALLER, M. A. Microbiologia Médica, 2013.

OLIVEIRA, W. A. Zika Vírus: histórico, epidemiologia e possibilidades no Brasil. Revista de Medicina e Saúde de Brasília., v. 6, n. 1, p. 96-107, 2017.

SOUZA, W. V. DE et al. Microcephaly in Pernambuco State, Brazil: epidemiological characteristics and evaluation of the diagnostic accuracy of cutoff points for reporting suspected cases. Cadernos de saúde pública, v. 32, n. 4, 2016.

\section{Como citar este artigo (Formato ABNT):}

PETRÔNIO, Cícera Nerilda V.; MELO, Antonio Marlos D. de; MESQUITA NETO, Edmar; SAMPAIO, José Angelo A.; TELLES, Maria Valéria Leimig; SOUZA, Conceição M. S. C. de. O Início da Epidemia do Zika Vírus e os seus Reflexos na Saúde Pública Nacional e Internacional. Id on Line Rev.Mult. Psic., 2018, vol.12, n.40, p.1232-1235. ISSN: 1981-1179.

Recebido: 28/05/2018

Aceito 30/05/2018 